\title{
Method of operator safety assessment for underground mobile mining equipment
}

\author{
Paulina Działak ${ }^{1, *}$, Jacek Karliński ${ }^{1}$, and Eugeniusz Rusiński ${ }^{1}$ \\ ${ }^{1}$ Wrocław University of Science and Technology, Mechanical Faculty, Department of Machine \\ Design and Research, 27 Wyb. Wyspianskiego St., 50-370 Wroclaw, Poland
}

\begin{abstract}
The paper presents a method of assessing the safety of operators of mobile mining equipment (MME), which is adapted to current and future geological and mining conditions. The authors focused on underground mines, with special consideration of copper mines (KGHM). As extraction reaches into deeper layers of the deposit it can activate natural hazards, which, thus far, have been considered unusual and whose range and intensity are different depending on the field of operation. One of the main hazards that affect work safety and can become the main barrier in the exploitation of deposits at greater depths is climate threat. The authors have analysed the phenomena which may impact the safety of MME operators, with consideration of accidents that have not yet been studied and are not covered by the current safety standards for this group of miners. An attempt was made to develop a method for assessing the safety of MME operators, which takes into account the mentioned natural hazards and which is adapted to current and future environmental conditions in underground mines.
\end{abstract}

\section{Introduction}

All structures (cabins) designed to protect operators of underground mining machinery that are to be put into operation in mines must comply with the requirements of the Machinery Directive 2006/42/EC. This document includes, among other things, two standards that describe tests performed on cabins and the criteria that must be met for the machine to be authorized for use. The purpose of these tests is to ensure the protection of operators of mobile mining equipment. These standards are: ISO 3449:2005 (FOPS - Falling-Object Protective Structures) and ISO 3471:2009 (ROPS - Roll-Over Protective Structures) [1]. In addition, Polish legislation also applies the PN-92/G-59001 standard (RSPS - Rock Slide Protective Structures; Fig. 1). It is designed to protect machine operators from the effects of roof falls. The first one (FOPS) is associated with the protection of operators against falling objects. The test consists in the drop of a cylindrical object onto the roof of the protective structure from a height sufficient to develop the required impact energy of $11600 \mathrm{~J}$. The testing procedure for RSPS is very similar to the FOPS test, with the difference that RSPS is performed with greater impact energy of at least $60 \mathrm{~kJ}$ [2]. The ROPS standard, however,

\footnotetext{
Corresponding author: paulina.dzialak@pwr.edu.p1
} 
is required for all self-propelled machines with a mass greater than $700 \mathrm{~kg}$ (described in ISO 6165), designed for an on-board seated operator. It is a static test in which the protective structure is subjected to standardized load that represents roll over situations [3].
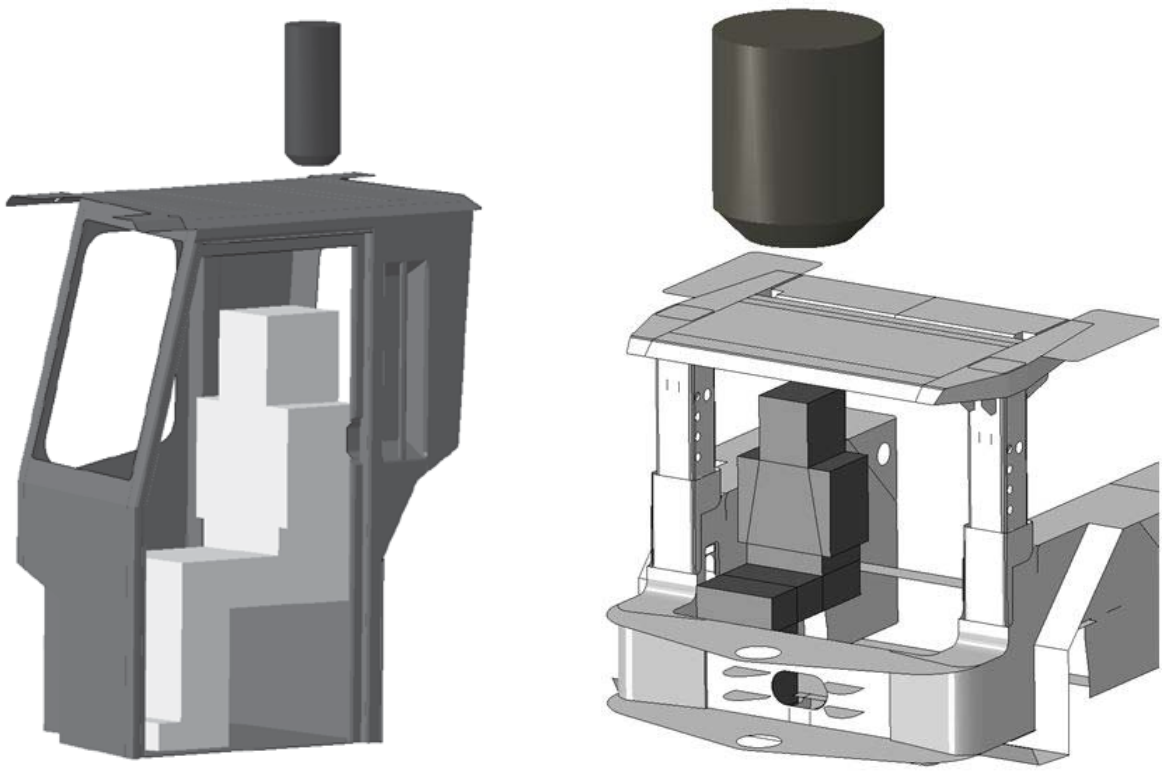

Fig. 1. FOPS test (left) and RSPS test (right); DLV placed inside the protective structure.

In standard tests, the DLV (Deflection Limiting Volume) is used to represent the operator (Fig. 1). It is an orthogonal approximation of a large seated operator that defines the deformation limits of the cab [4]. Tests are considered positive if none of the elements of the protective structure that has been punctured or deformed in the elastic and plastic range enter the protective space defined by the DLV [5]. Due to the required distance between the model and the structure, the sufficient condition is that no part exceeds the dynamic deflection value of $50 \mathrm{~mm}$. However, no tests are performed to determine the loads acting on the body of the operator or the injuries that an operator may sustain during the accident.

On the other hand, an analysis of accidents in underground mining with respect to machine operators indicates that there are accidental situations in which the DLV is not penetrated but the operator still sustains severe or even fatal injuries. Once the deposit is depleted on the current level, mining proceeds to deeper levels where geological and mining conditions are different. These conditions activate natural hazards which differ in intensity and range, resulting in events that have thus far been considered extraordinary $[6]$.

The authors have decided to propose a new method of testing the safety of operators of machines intended for underground mining. The method takes into account both the injuries that could be sustained by the operator located in the protective structure as well as the effects of dynamic phenomena, which have not been analysed yet, but which are becoming a major threat to work safety in underground mines as the depth of mining increases. 


\section{Methodology of research}

The proposed method is based on numerical analysis of events that are dangerous to operators of underground mining machinery. It involves tests on a complete numerical model of the protective structure with a full-size operator dummy as well as a seat with a lap belt and a simplified model of its mount. This specially devised model is then subjected to loads that represent those generated by dangerous phenomena acting on the cab. First it is necessary to identify the phenomena that may be hazardous or fatal to operators and this should be followed by the formulation of appropriate boundary conditions that best reflect the actual event [7].

\subsection{Identification of hazards}

Based on the results of a statistical analysis of underground mining accidents, with special consideration of copper mines, it was possible to identify the most dangerous phenomena that threaten the safety of machine operators. Apart from the dangers associated with roof collapses and rocks falling from the ceiling and sidewalls, which have already been identified by current safety standards, new phenomena are emerging that have previously been unheard of. One such new danger that has appeared in recent years is the upthrow of machinery caused by sudden floor uplift or by the rapid filling of the loader bucket with the extracted material. Due to the low height of the mine gallery the machine that is ejected upwards often hits the ceiling. The same happens to the operator protective structure on the machine. However, neither the cabin load-carrying structure nor its attachment are adapted to such loads. This is also true for the operator's seat and the safety systems inside the protective structures. Such incidents can be harmful or fatal to operators, which has been confirmed by the accidents that have taken place thus far [8] (Fig. 2).
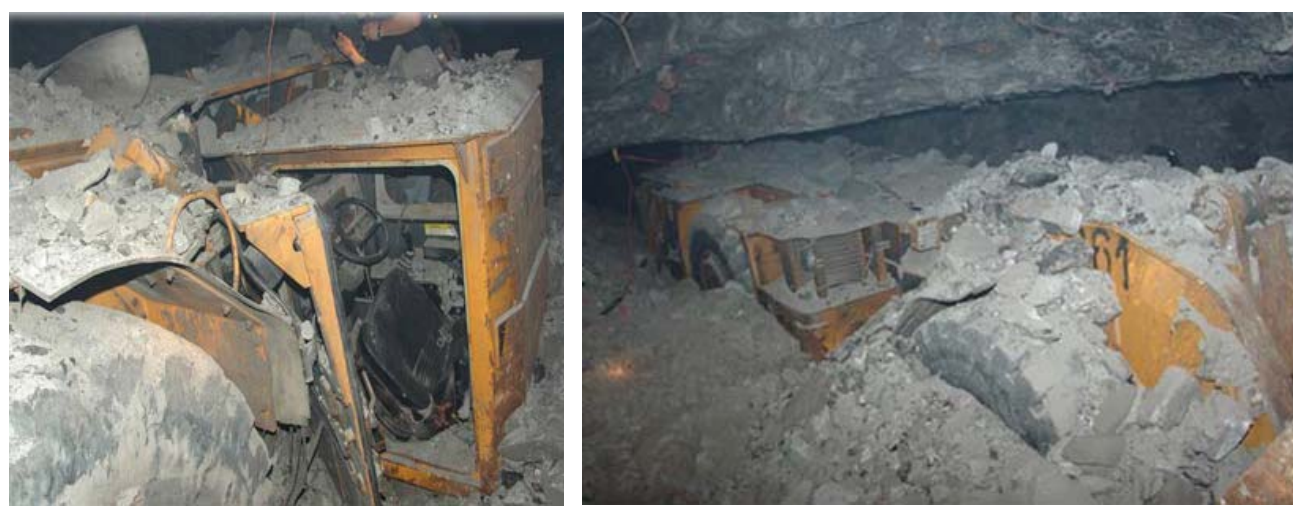

Fig. 2. Damage resulting from the upthrow of machinery caused by a rock burst.

\subsection{Positioning}

The developed numerical model combines the Finite Element Method (FEM) [9] with MultiBody (MB) models and uses the advantages of both numerical codes [10]. By combining these two systems it is possible to perform a complete strength analysis [11] of the protective structure and of the injuries to the operator, while significantly reducing the required calculation time. The numerical model prepared by the authors is based on three basic components: the MADYMO dummy, the operator protective structure and the operator's seat with the mount and a two-point seat belt. 


\subsubsection{Dummy}

The authors have decided to abandon the standard approach to operator safety tests and include a full-scale human model in the testing procedure. This was achieved by selecting the appropriate numerical model of the operator, whose design allowed for the collection of all the required data resulting from specific dynamic loads generated by rock bursts in the mine. A comparison was made between numerical equivalents of three dummies that are used in vehicle and road transport safety tests - Hybrid II and Hybrid III, as well as aircraft tests - Hybrid III FAA (Federal Aviation Administration). The simulations were based on ellipsoid MADYMO dummies (Fig. 3). This system offers access to a complete database of validated numerical dummies that are ready for testing [12].
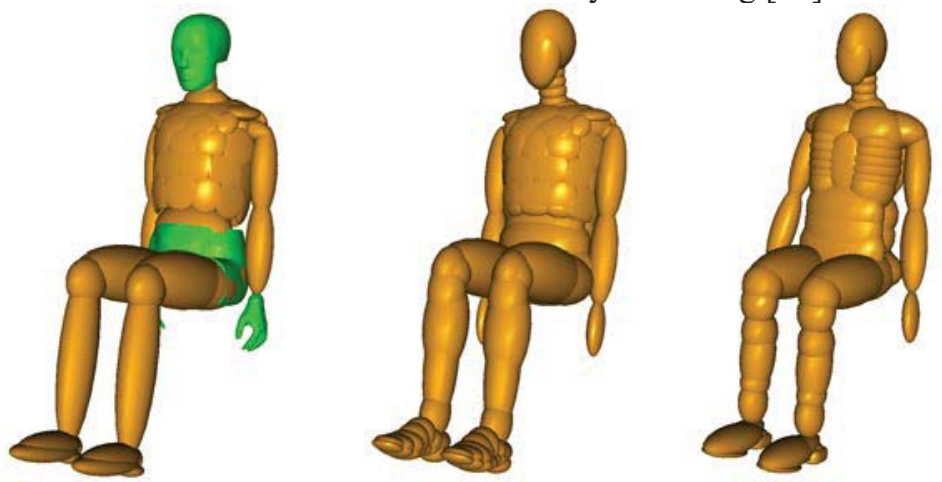

Fig. 3. MADYMO dummies used in the comparative analysis; from left to right: Hybrid II, Hybrid III and Hybrid III FAA.

Given the typical size and gender of operators of self-propelled machinery designed for underground mining, the studies compared 50th percentile male dummies (with approximate height and weight of $175 \mathrm{~cm}$ and $75 \mathrm{~kg}$ respectively). For the purpose of this comparative analysis, a simplified model of the seat with cabin elements has been developed, which the operator's body can come into contact with during the incident. This model was based on perfectly rigid surfaces so that results can be compared between different human body models without the necessity to analyze additional variables (Fig. 4). The dummies were also fitted with a lap belt, which should be used by every operator at all times.

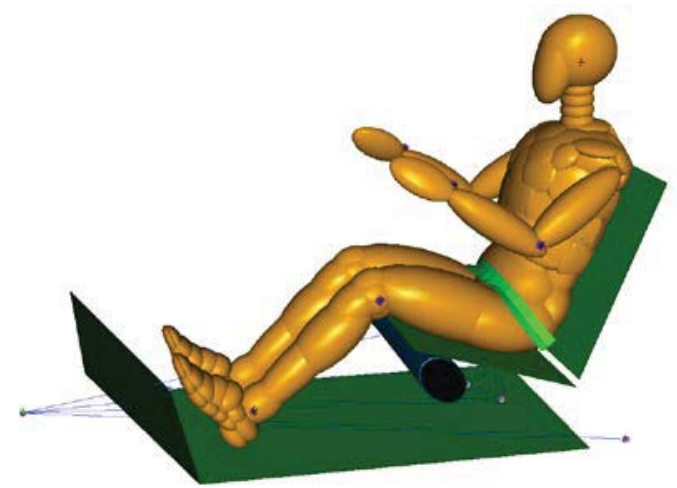

Fig. 4. Model developed for comparative analysis of dummies. 
Eventually, the Hybrid III FAA dummy was selected for further analysis as it is best suited to respond to and process vertical loading, particularly in sections of the spine and upper legs [13], and it is those vertical forces that will be dominant in cases analyzed by the authors.

\subsubsection{Seat}

The geometric model of the operator's seat was not available and was therefore obtained by capturing the shape of the actual seat. This was achieved by means of TRITOP and ATOS optical systems. TRITOP is a portable device that measures the coordinates of selected three-dimensional objects. This system was used to represent the geometry of the foam seat and backrest. ATOS, on the other hand, is a 3D scanner which delivers accurate and complete measurement data, even in the case of complex and glossy elements [14]. In this case it was used to obtain the geometry of the frame of the seat (Fig. 5). By combining the abovementioned systems a full and detailed geometry of the operator's seat was obtained, which, after discretization, was included in the simulation.

a)

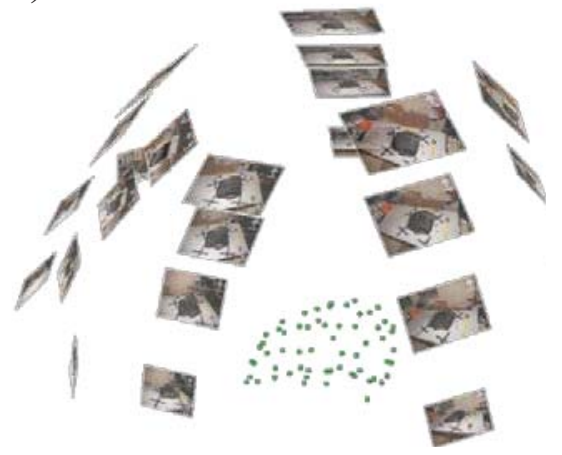

b)

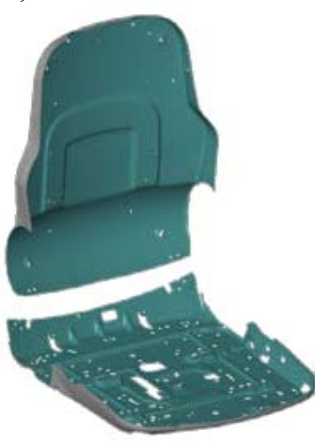

c)

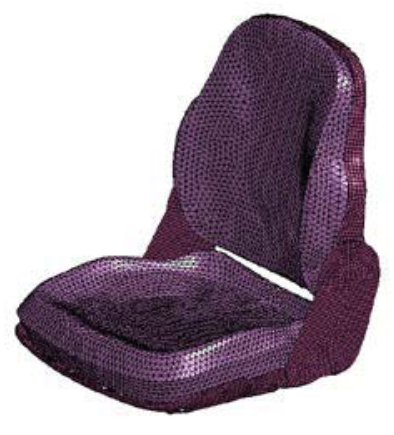

Fig. 5. Development stages of the operator seat model: a - measuring with the TRIROP system, $\mathrm{b}$ - scan made with the ATOS system, $\mathrm{c}$ - final numerical model of the seat.

\subsubsection{Protective structure}

The protective structures that were analyzed are cabins which are already in use and thus meet the current safety standards for machine operators. Based on the geometry, a discrete model was developed, which, in this instance, was tested in accordance with the new method proposed by the authors. Discretization was performed using triangular and rectangular low-order shell elements of the explicit type [15], with edge length of about $15 \mathrm{~mm}$. The final computational model of the cabin with the dummy and operator's seat is shown in Figure 6. 


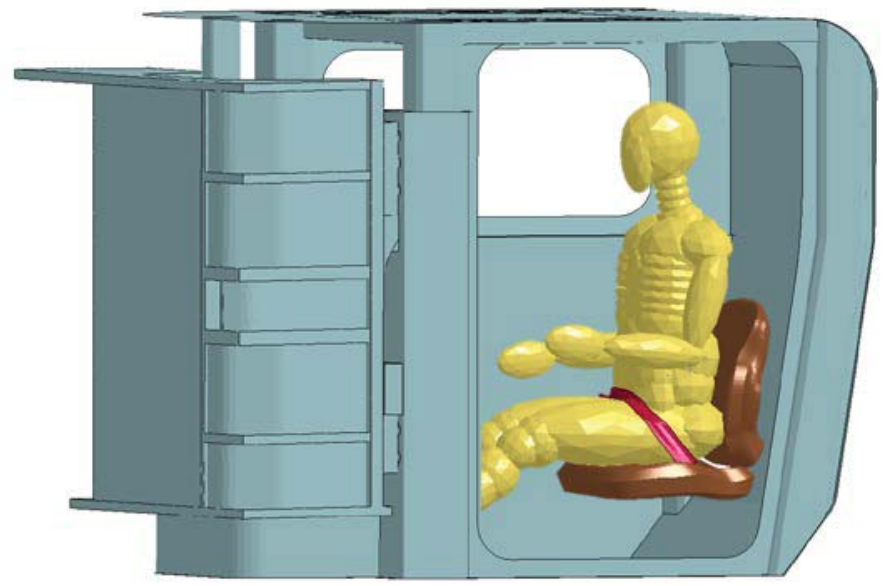

Fig. 6. Final model of the studied cabin with the dummy and operator seat.

\section{Analysis of results}

The proposed method includes an analysis of injuries sustained by biomechanical parts of the body, whose damage can lead to death or disability (physical impairment of the organism leading to limitation of bodily functions without a reasonable chance for recovery) [16]. Given the loads acting on machine operators during different accidents, the parts of the body most vulnerable to injury are the spine, head, and neck. The authors have decided to take into account the following criteria of injury:

- vertical load measured in the lower section of the lumbar spine;

- HIC (Head Injury Criterion);

- Nij (Neck Injury Criterion).

The US Federal Aviation Administration (FAA) established the safety testing conditions for aircraft and seats in the event of an emergency landing. One of the criteria for spinal injuries that is included is the vertical force acting on the spinal column, measured in the lumbar section of a 50th percentile male dummy. This criterion states that such force cannot exceed $6672 \mathrm{~N}$ [17]. On the other hand, the US military regulations regarding loads acting on the spine in combat helicopters define the permissible forces on the basis of the maximum acceleration value that is safe for the spinal column $(14.5 \mathrm{~g})$. For a standard male dummy the permissible force level is as high as $9185 \mathrm{~N}$ [18]. In the case of mining machinery operators this criterion should be verified by accurately adapting it to this group adapted to this particular group. However, assuming that operators are mostly men at a relatively young age, the authors, in their studies, have adopted the criterion of the American army as the limit value.

HIC is a criterion which describes the likelihood of a head injury during an accident. The time-history of head accelerations that is necessary to calculate the HIC value is most often read from the accelerometer located at the center of gravity of the head of the dummy, which is subjected to appropriate loads. This criterion is described by the following formula (1)

$$
H I C=\left(\left[\frac{1}{t_{2}-t_{1}} \int_{t_{1}}^{t_{2}} a(t) d t\right]^{2.5}\left(t_{2}-t_{1}\right)\right)_{\max }
$$


where $t_{1}$ and $t_{2}$ are respectively the initial and final times (expressed in seconds) of the interval during which the load acting on the head attains maximum value whereas $a$ is the acceleration (expressed in $g$ ). The maximum time duration $\left(t_{2}-t_{1}\right)$ is generally limited to 3$36 \mathrm{~ms}$, and is typically $15 \mathrm{~ms}$. This means that HIC takes into account both the value and duration of the loading. The permissible HIC level at which no severe injury or disability occurs is 1000 [19].

The Nij criterion is the likelihood of injury to the cervical spine. It combines injuries associated with neck axial loads $\left(F_{z}\right)$ and bending moment to the neck $\left(M_{O C y}\right)$ compared to the critical values $\left(F_{z c}, M_{y c}\right)(2)$ defined by the standard [20] and can be crucial when analyzing severe injuries to operators resulting from strong jolts. According to the literature [21], for $N i j$ equal to 0.5 the probability of sustaining AIS $\geq 3^{\dagger}$ injury is minimized to 0.1 , which is why the authors have adopted this value as appropriate for the health and safety of operators.

$$
N_{i j}=\frac{F_{z}}{F_{z c}}+\frac{M_{O C y}}{M_{y c}}
$$

All of the mentioned criteria can be obtained directly in the MADYMO software, which acquires them from appropriate dummy sensors. Table 1 presents a comparison between the results obtained from the analysis of a sample protective structure during an upward thrust of the machine (in the worst case when machine ejection velocity is $10 \mathrm{~m} / \mathrm{s}$ ) and the limits of the injury criteria.

Table 1. Comparison between limit values and values obtained during a sample simulation.

\begin{tabular}{|c|c|c|}
\hline Criterion & Limit value & $\begin{array}{c}\text { Obtained } \\
\text { value }\end{array}$ \\
\hline $\begin{array}{c}\text { Vertical load } \\
\text { on the spine } \\
{[\mathrm{kN}]}\end{array}$ & 9,2 & 30.3 \\
\hline HIC & 1000 & 1440 \\
\hline Nij & 0.5 & 1.4 \\
\hline
\end{tabular}

The cabin analyzed in this case complies with all the standard requirements and is implemented for operation in an underground mine. However, the results presented in Table 1, which were obtained using the original method proposed by the authors, suggest that this structure is not safe for the operator.

\section{Summary and conclusions}

The analysis of accident incidence rate in underground mining over the last dozen years, mainly in terms of machine operators, indicates an urgent necessity to improve their safety. As extraction reaches into deeper layers of the deposit and conditions become increasingly difficult, the number of uncontrolled phenomena occurring inside the rock mass continuously increases and poses a serious threat to the health and safety of miners. Previous studies of protective structures focusing on machine operator safety have been carried out using the DLV, which is a volume that simulates the safety zone of a seated

\footnotetext{
${ }^{\dagger}$ AIS (Abbreviated Injury Scale) - a six point scale that determines the severity of injury in individual regions of the human body; 1 - minor, 2 - moderate, 3 - serious, 4 - severe, 5 critical, 6 - maximal (untreatable) [22, 23].
} 
operator that must remain intact during the test. The DLV is not equipped with any sensors, nor does it reproduce the shape of the human body. Hence it is impossible to analyze the loads that act on the operator's body and the injuries that are sustained in accidents caused by various phenomena occurring in underground mines. However, the situations that have occurred thus far indicate the need to monitor injuries sustained by operators, which may be very severe even when protective structures comply with standard safety requirements. Studies should also include other dynamic phenomena resulting from rock bursts, which are not included in the current analyses, but which pose a significant threat to the health and safety of operators.

The authors have proposed a new safety testing method which, apart from evaluating the entire protective structure, also includes a full model of the operator's body as well as the operator seat with its geometrical and material properties and a simplified model of its attachment to the cabin. The prescribed motion has been defined based on a review of literature. The results of tests performed with the application of this approach will provide a better understanding of the biomechanics of injuries that operators may sustain and will enable the continuation of research aimed at improving their safety, e.g. by introducing new protective systems.

This study described it this article involved a simulation of a dangerous accident where a machine is ejected upwards. Thus far, this phenomenon has not been taken into account in operator safety studies, but it remains a serious threat, as evidenced by accidents that have already occurred in mines. Tests were performed using a cabin that meets the requirements of current regulations. The results indicate that injuries suffered in the event of such phenomena significantly exceed the permissible values of criteria and further research is needed to improve the safety of operators of underground mining machines.

Research is co-financed by the National Science Centre Poland within the framework of the project "The assessment of the seismic phenomena effects in the aspect of the operator safety" no. 2015/17/N/ST8/01212.

\section{References}

1. J. Karliński, E. Rusiński, T. Smolnicki, Autom. Constr. 17, 232 (2008)

2. M. Kalita, Min. Mach. 1, 16 (2013)

3. J. Karliński, M. Ptak, P. Działak, Arch. Civ. Mech. Eng. 13, 57 (2013)

4. S. Kaneda, T. Tamagawa, Komatsu Tech. Rep. 49, 2 (2003)

5. N. J. Perera, D. P. Thambiratnam, B. Clark, Australas. J. Min. Saf., 3, 68 (2011)

6. J. Butra, Eksploatacja złoża rud miedzi w warunkach zagrożenia tapaniami i zawałami, KGHM Cuprum, Wrocław (2010)

7. A. Goszcz, Elementy mechaniki skat oraz tapania $w$ polskich kopalniach wegla $i$ miedzi, SEP, Kraków (1999)

8. WUG, Raport o stanie bezpieczeństwa pracy w polskich kopalniach (2017)

9. E. Rusiński, P. Moczko, D. Pietrusiak, J. Mech. Eng. 59, 556 (2013)

10. M. Ptak, E. Rusiński, J. Karliński, S. Dragan, Arch. Civ. Mech. Eng. 12, 68 (2012)

11. T. Smolnicki, M. Stańco, D. Pietrusiak, Tech. Gaz. 20, 831 (2013)

12. https://www.tassinternational.com/madymo-dummy-models, (2017)

13. FAA, Hybrid II and Federal Aviation Administration Hybrid III Anthropomorphic Test Dummy Dynamic Evaluation Test Series, NTIS, Springfield, Virginia (2013)

14. http://www.gom.com/metrology-systems.html, (2017) 
15. T.J.R. Hughes, The Finite Element Method: Linear Static and Dynamic Finite Element Analysis, Dover, New York (2000)

16. https://www.mpips.gov.pl/ubezpieczenia-spoleczne/ubezpieczeniawypadkowe/definicje-zawarte-w-ustawie-o-ubezpieczeniu-spolecznym-z-tytuluwypadkow-przy-pracy-i-chorob-zawodowych/uszczerbek-na-zdrowiu (2017)

17. FAA Regulation 29 - Airworthiness standards: Transport category rotorcraft, Emergency landing conditions (2017)

18. S.P. Desjardins, AHS J. 51, 150 (2006)

19. K. Jamroziak, Modell. Eng. 42, 179 (2011)

20. NHTSA, Development of improved injury criteria for the assessment of advanced automotive restraint systems, Washington, DC (2011)

21. B.D. Stemper, N. Yoganandan, F.A. Pintar, B.S. Shender, G.R. Paskoff, Aviat. Space Environ. Med. 80, 489 (2009)

22. T.A. Gennarelli, E. Wodzin, Inj. 37, 1083 (2006)

23. P.M. Cartera, C.A.C. Flannagana, M.P. Reeda, R.M. Cunninghama, J.D. Rupp, Accid. Anal. Prev. 72, 146 (2014) 